Gynäk. Rdsch. 1978;18:155

\title{
Redaktionelle Mitteilung
}

Als neue Mitarbeiter in der Redaktion der ,,Gynäkologischen Rundschau” seien die Herren Prof. H. Hirsch, Direktor der Universitäts-Frauenklinik Tubingen, und Prof. E. Gitsch, Vorstand der I. Universitäts-Frauenklinik Wien, herz-lich willkommen geheissen.

Prof. E. Gitsch setzt in freundlicher Weise den Kondensateteil der Zeit-schrift in Nachfolge des verstorbenen Herrn Prof. H. Schwalm fort.

M. Berger, Bern 